\title{
A Coordinated Optimization Model of the Complex System of the Green Supply Chain Distribution Network
}

\author{
Yurong Guan, ${ }^{1}$ Muhammad Aamir, ${ }^{1}$ Zaheer Ahmed Dayo $\left(\mathbb{D},{ }^{1}\right.$ Ziaur Rahman, ${ }^{1}$ \\ Waheed Ahmed Abro, ${ }^{1}$ Irfan Ali, ${ }^{2}$ and Zhihua $\mathrm{Hu} \mathbb{D}^{1}$ \\ ${ }^{1}$ Department of Computer Science, Huanggang Normal University, Huanggang 438000, China \\ ${ }^{2}$ Department of Computer Systems Engineering, MUET, Jamshoro, Sindh, Pakistan \\ Correspondence should be addressed to Zhihua Hu; huzhihua@hgnu.edu.cn
}

Received 13 July 2021; Revised 1 August 2021; Accepted 4 August 2021; Published 13 August 2021

Academic Editor: Daqing Gong

Copyright (C) 2021 Yurong Guan et al. This is an open access article distributed under the Creative Commons Attribution License, which permits unrestricted use, distribution, and reproduction in any medium, provided the original work is properly cited.

\begin{abstract}
A well-established distribution network is fundamental to the sound management of the green supply chain. To adapt to the market demand and policies for green products, it is urgent to build an efficient and rational logistic distribution network for the green supply chain. Many researchers have tried to design distribution networks through the coordinated optimization of the green supply chain, in the light of realistic situation. However, there are very few optimization models that consider all kinds of influencing factors. To solve the problem, this paper attempts to establish a coordinated optimization model of the complex system of the green supply chain distribution network (GSCDN). Firstly, the authors plotted the structure and game logic of the GSCDN and defined the upper limit of sales induced by the limited production capacity of producers. Secondly, the coordinated optimization conditions were configured for the distributor layer, producer layer, and market demand layer, and a coordinated optimization model was set up for the complex system. Finally, the contractual coordinated optimization mechanism was detailed for the complex system under the profit-sharing contract. The proposed model and solving algorithm were proved valid through experiments.
\end{abstract}

\section{Introduction}

The growing market demand for green products brings about multifaceted challenges and pressures to green producers and sellers: expediting the delivery, reducing the cost, improving the quality, and ensuring the timeliness of distribution [1-5]. It is impossible to cope with these through the resource optimization and integration by a single producer or seller. For a supply chain to stand out from its competitors, all players of the supply chain, including raw material suppliers, manufacturers, distributors, retailers, and consumers, must cooperate with each other $[6,7]$. As a complex system, the distribution network is critical to successful management of green supply chain $[8,9]$. To adapt to the market demand and policies for green products, as well as the development needs of producers and sellers, it is urgent to build an efficient and rational logistic distribution network for green supply chain.
The slow service and high cost of supply chain logistics mainly come from the lack of information sharing between relevant parties and the conflicts between the inventory of producers and the distribution by distributors [10-16]. Holjevac et al. [17] analyzed the structure and features of the supply chain for engineering machinery producers and built a cooperative game model for the supply chain to optimize both inventory and distribution. Based on the shared sales information of green supply chain, Liao [18] designed an intelligent algorithm capable of precisely determining the raw material demand and proposed a distribution optimization strategy based on inventory and demand. To balance the logistics costs between suppliers and producers, De Corte and Sörensen [19] fully considered such constraints as the proportional supply by multiple suppliers, introduced the cost subsidy to the game model of the supply chain, and improved the particle swarm optimization (PSO) to support the intelligent, fast, and optimal decision-making of batch 
size and frequency of distribution. Li et al. [20] examined the features of e-commerce distribution models, summarized the considerations of enterprises in determining distribution models upon joining e-commerce platforms, and established a game model for cooperative distribution services. Based on this model, they evaluated how each factor influences the operation state of platform distribution service chain and the behavior decision-making by the participants. The above review of domestic and foreign literature shows the following: (1) Green supply chain distribution network (GSCDN) is a complex organic body. Under the rapid changes of the market, brand-new supply chain management ideas are needed to deliver satisfactory products to consumers at minimum cost and fastest speed from the angle of green supply chain management and construct a logistics network based on supply chain. (2) In the management environment of green supply chain, the optimization of logistics network usually focuses on the logistics facility sites and distribution paths. It is particularly important to build a suitable optimization model.

Many scholars at home and abroad have tried to optimize the site of distribution centers for supply chains and streamline the distribution paths [21-29]. However, relatively few of them have constructed distribution networks for the coordinated optimization of green supply chain. Also, not many researchers developed optimization realistic models, which consider factors like cost, environment, and transport. Therefore, this paper attempts to build a coordinated optimization model for the complex system of GSCDN. Section 2 plots the structure and game logic of GSCDN and defines the upper limit of sales induced by the limited production capacity of producers. Section 3 configures the coordinated optimization conditions for the distributor layer, producer layer, and market demand layer and sets up a coordinated optimization model for the complex system. Section 4 presents the contractual coordinated optimization mechanism for the complex system, under the profitsharing contract. Section 5 describes the solving method for the model based on the adaptive genetic algorithm. The proposed model and solving algorithm were proved valid through experiments.

This paper systematically analyzes the coordination of logistics network under the management environment of green supply chain, constructs and optimizes a reasonable GSCDN model, and tries to optimize the established network. The research results provide a reference for the building of an efficient GSCDN and beneficial evidence to the optimal site selection of distribution centers.

\section{System Structure and Game Logic}

The concept of green supply chain was first proposed by the manufacturing research association of Michigan State University in 1996 in a study on "environmentally responsible manufacturing (ERM)." Also known as environmentally-aware supply chain or environmental supply chain, the green supply chain is a modern management model that fully considers the environmental impact and resource efficiency in the entire supply chain. Based on green manufacturing theory and supply chain management technology, the green supply chain tries to minimize the environmental impact and maximize the resource efficiency of products from material acquisition, processing, packaging, warehousing, transportation, and utilization to waste disposal.

The complex system of GSCDN consists of raw material suppliers, producers, distributors, retailers, and consumers. Among them, distributors own several distribution stations and centers. By integrating the transaction relationships between these parties, it is possible to plot the structure of the complex system for a GSCDN (Figure 1).

Let $i$ be the $i$ th distributor participating in the operation of the GSCDN, $\forall i \in\{1,2, \ldots, N\}$; let $j$ be the $j$ th producer in the market of the green supply chain, $\forall j \in\{1,2, \ldots, M\}$; let $l$ be the green product market of the complex system, $\forall l \in\{1$, $2, \ldots, e\}$; let $\phi$ be the transaction method between a distributor and a producer; if $\phi=1$, the two parties adopt contractual sales; if $\phi=2$, the two parties adopt free sales.

The green products and their production process have the following advantages: saving energy, saving water, low pollution, low toxicity, and being renewable and recyclable. These products are the ultimate manifestation of the application of green technology. Green products can directly promote the transformation of our consumption concepts and production methods. The defining feature of these products is to achieve environmental protection through market regulation. As the purchase of green products becomes fashionable among the public, enterprises are encouraged to obtain economic benefits through the production of green products.

The logic map (Figure 2) of the complex system for the GSCDN provides the game objectives of each subject in that system. Retailers and consumers aim to reduce the cost and improve the timeliness. Distributors eye high incomes facing retailers or consumers and low costs facing producers. Producers intend to have low costs facing raw material suppliers and high incomes facing distributors. Raw material suppliers strive to increase their incomes. In our coordinated optimization network, there are three levels of participants: producers, distributors, and retailers/consumers.

Distributors have price discrimination against producers, varying in production capacity and market share. Let $\mathbb{R}_{+}{ }^{N}$ be an $n$-dimensional Euclidean space; let $T C_{i j}^{1}$ be the contractual sales volume between $N$ distributors and $M$ producers, where $T C_{i} \in \mathbb{R}_{+}{ }^{N}$; let $\xi_{i j}{ }^{1}$ be the contractual sales volume between the $i$ th distributor and the $j$ th producer, which is a component of matrix $T C_{i j}^{1}$; let $\xi_{j}^{G E}$ be the maximum sales volume of a producer constrained by its production capacity. After summing up the data of the aforementioned parameters, the upper limit on the sales of a producer brought by the limited production capacity can be determined by

$$
\sum_{i=1}^{N} \xi_{i j}^{1} \leq \xi_{j}^{G E}
$$




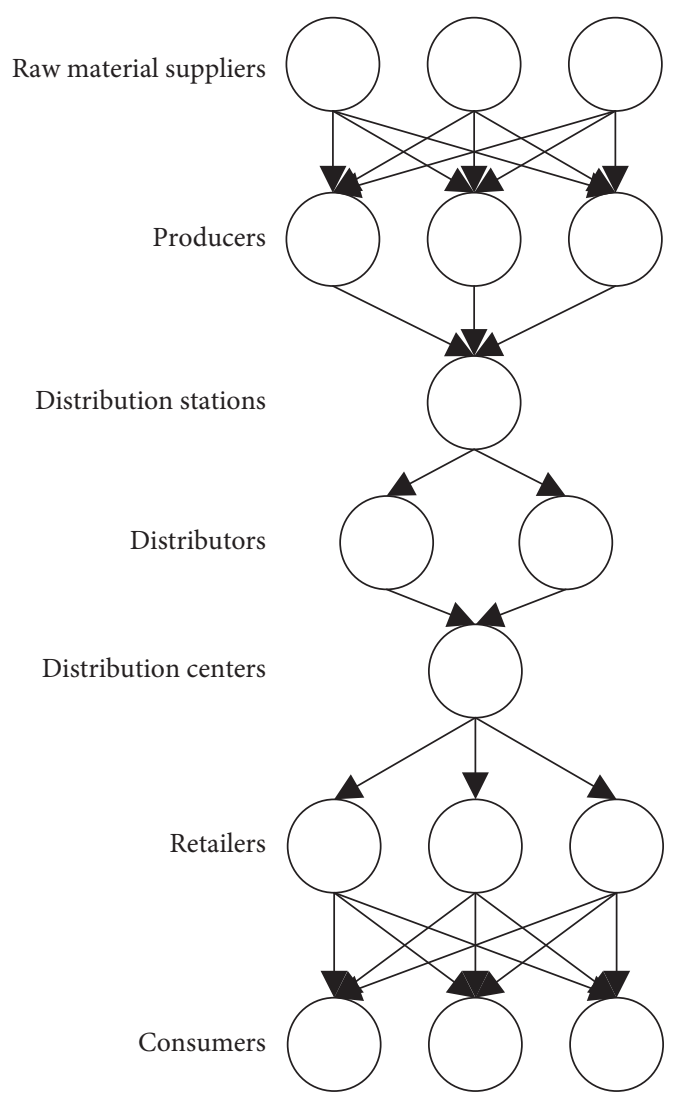

Figure 1: Structure of the GSCDN.

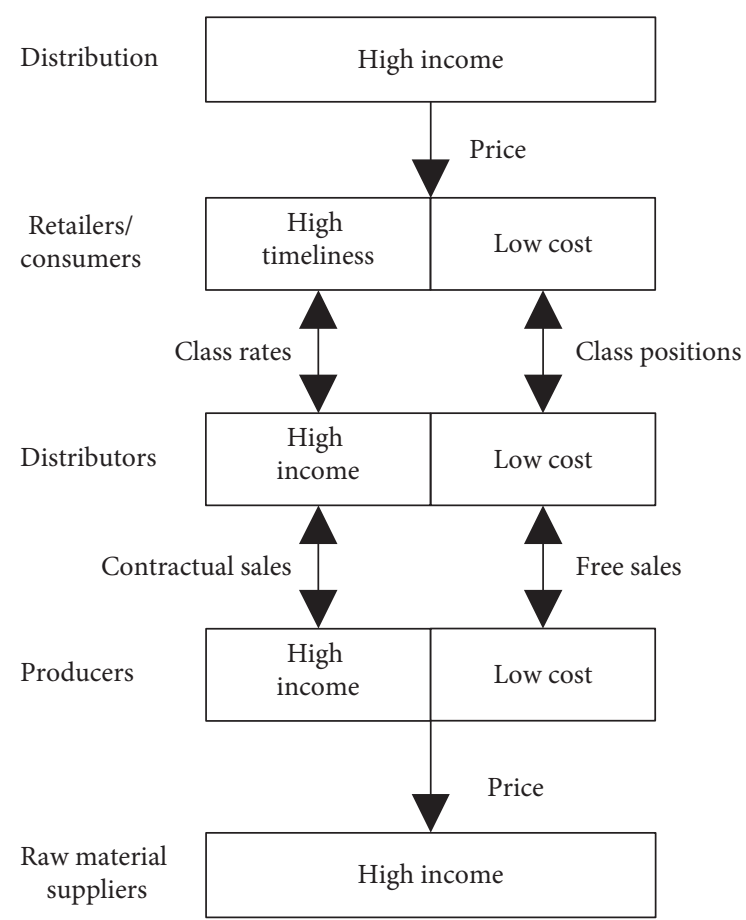

Figure 2: Game logic of the complex system for the GSCDN.

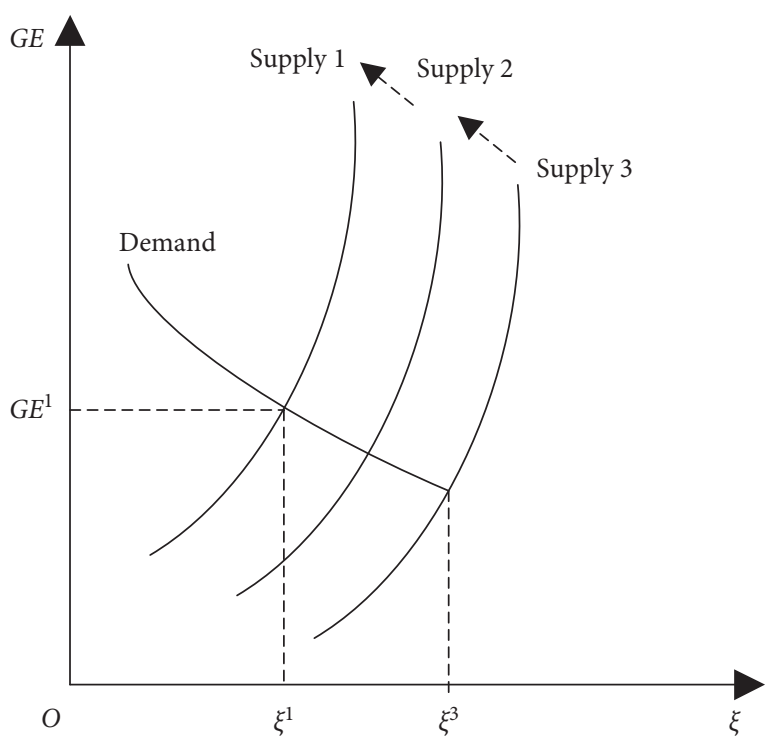

FIGURE 3: Coordinated optimization of the complex system for the GSCDN.

\section{Construction of the Coordinated Optimization Model}

3.1. Coordinated Optimization Conditions of the Distributor Layer. Figure 3 illustrates the coordinated optimization of the complex system for GSCDN. Suppose that the green product market meets the supply-demand balance. Since the distributors deliver products in full truckloads, it is assumed that the supply volume of a distributor equals its sales volume. Let $T C_{i j}{ }^{2}$ be the free sales matrix of $N$ distributors and $M$ producers, where $T C_{i j}{ }^{2} \in \mathbb{R}_{+}{ }^{N+M^{M}}$; let $\xi_{i j}{ }^{2}$ be the volume of free sales from the $i$ th distributor to the $j$ th producer, that is, a component of matrix $T C_{i j}{ }^{2}$. In the GSCDN, the total distributed volume $T C_{i}$ by the $i$ th distributor in the market can be calculated by

$$
T C_{i}=\sum_{j=1}^{M}\left(\xi_{i j}^{1}+\xi_{i j}^{2}\right) .
$$

Distributors differ significantly in business strategy, green product preference, and corporate strength. There is an upper limit on the volume of green products that a distributor can provide to the market: $0<T C_{i}<\xi_{i}^{G E}$. Due to the uncertain market demand of green products, the distributor's selling and distribution can be divided into the contractual sales between the distributor and the supplier in the early phase and the free sales and distribution between the distributor and the retailer and logistics company in the latter phase. Let $\xi^{1 G E}$ be the upper limit on the contractual sales volume of the $i$ th distributor, where $0<\xi_{i}^{1}<\xi_{i}^{1 G E}$. Then, the total volume of contractual sales $\xi_{i}^{1}$ can be calculated by

$$
\xi_{i}^{1}=\sum_{j=1}^{M} \xi_{i j}^{1} .
$$


Let $C_{P R-i}$ and $C_{M A-i}$ denote the distribution cost and operating cost of freight transport by the ith distributor, respectively. Then, the total operating cost of the $i$ th distributor is composed of two parts: $C_{P R-i}$ and $C_{M A-i}$. When the truckload distribution cost remains fixed, the operating cost of the $i$ th distributor $C_{M A-i}$ depends on both the distribution volume and the competition with other distributors in the market:

$$
C_{i}=C_{M A-i}+C_{C R-i}=C_{M A-i}^{1}+C_{M A-i}^{2}+C_{P R-i} .
$$

Let $G E_{i j}^{1}$ and $G E_{i j}^{2}$ be the green product prices under contractual model and free model between the $i$ th distributor and the $j$ th producer, respectively. Then, the profit of the distributor, that is, the difference between the income and cost of green product sales, can be maximized by

$$
\begin{aligned}
& \operatorname{Max} \sum_{j=1}^{M}\left(G E_{i j}^{1} \xi_{i j}^{1}-C_{M A-i}\left(T C_{i j}^{1}\right)\right)+\sum_{j=1}^{M}\left(G E_{i j}^{2} \xi_{i j}^{2}-C_{M A-i}\left(T C_{i j}^{2}\right)-C_{P R-i}\left(T C_{i j}^{2}\right)\right), \\
& \text { s.t. }\left\{\begin{array}{l}
\sum_{j=1}^{M} \xi_{i j}^{1} \leq \xi_{i}^{1 G E}, \\
\sum_{j=1}^{M}\left(\xi_{i j}^{1}+\xi_{i j}^{2}\right) \leq \xi_{i}^{G E}, \\
\xi_{i j}^{1} \geq 0, \xi_{i j}^{2} \geq 0 .
\end{array}\right.
\end{aligned}
$$

Model (5) is a superposition between the income-cost difference of the $i$ th distributor in the contractual model and that in the free model.
According to the equivalence between variational inequality and optimization problem, the optimal solution to the distributor's profit maximization model (5) is equivalent to the solution to the following variational inequality:

$$
\sum_{j=1}^{M}\left(\frac{\partial C_{M A-i}\left(T C_{i j}^{1 *}\right)+\partial C_{P R-i}\left(T C_{i j}^{1 *}\right)}{\partial \xi_{i j}^{1}}-G E_{i j}^{1 *}\right) \cdot\left(\xi_{i j}^{1}-\xi_{i j}^{1 *}\right)+\sum_{j=1}^{M}\left(\frac{\partial C_{M A-i}\left(T C_{i j}^{2 *}\right)+\partial C_{P R-i}\left(T C_{i j}^{2 *}\right)}{\partial \xi_{i j}^{2}}-G E_{i j}^{2 *}\right) \cdot\left(\xi_{i j}^{2}-\xi_{i j}^{2 *}\right) \geq 0
$$

The profit maximization model can be interpreted by optimality conditions. The first part of the model is the volume of contractual sales by the distributor to the market, and the second part is the volume of free sales between the distributor and the producer. The optimality conditions for all distributors can be described as in the following variational inequality:

$$
\sum_{i=1}^{N} \sum_{j=1}^{M}\left(\frac{\partial C_{M A-i}\left(T C_{i j}^{1 *}\right)+\partial C_{P R-i}\left(T C_{i j}^{1 *}\right)}{\partial \xi_{i j}^{1}}-G E_{i j}^{1 *}\right) \cdot\left(\xi_{i j}^{1}-\xi_{i j}^{1 *}\right)+\sum_{i=1}^{N} \sum_{j=1}^{M}\left(\frac{\partial C_{M A-i}\left(T C_{i j}^{2 *}\right)+\partial C_{P R-i}\left(T C_{i j}^{2 *}\right)}{\partial \xi_{i j}^{2}}-G E_{i j}^{2 *}\right) \cdot\left(\xi_{i j}^{2}-\xi_{i j}^{2 *}\right) \geq 0
$$

3.2. Coordinated Optimization Conditions of Producers. Figure 4 illustrates the structure of the coordinated optimization for GSCDN. In the green product supply and distribution service chain, each producer is responsible for processing and supplying green products and linking up distributors, end consumers, and suppliers. It makes profit from the price gap between raw materials and green products. According to its own production capacity and the actual situation of the distribution market, the $j$ th producer determines an upper limit $\xi_{j}^{1 G E}$ of the sales volume for the contractually purchased products, where $0 \leq \xi_{j}^{1} \leq \xi_{j}^{1 G E}$. Then, the total sales volume $\xi_{j}^{1}$ for the contractually purchased products of the $j$ th producer can be calculated by

$$
\xi_{j}^{1}=\sum_{j=1}^{M} \xi_{i j}^{1}
$$

Let $C_{P U-j}$ and $C_{M A-j}$ be the purchase cost of raw materials for green products and the operating cost of freight transport of the $j$ th producer, respectively. Similarly, the total operating cost of the $i$ th producer is composed of two parts: $C_{P U-j}$ and $C_{M A-j}$ : 


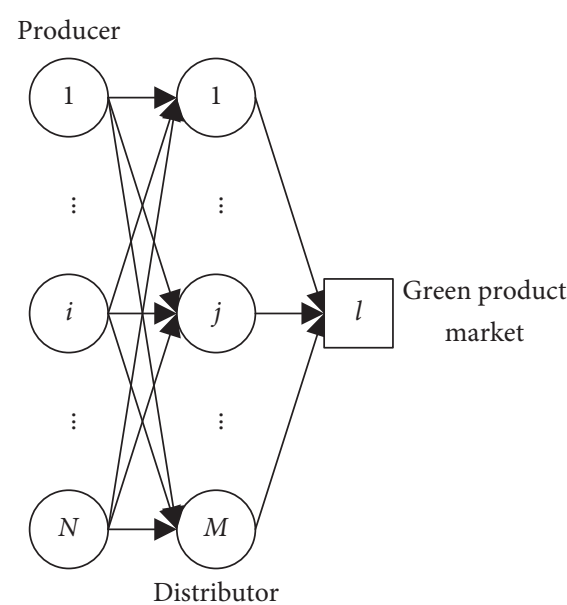

FIGURE 4: Structure of the coordinated optimization for the GSCDN.

$$
C_{j}=C_{P R-j}+C_{M A-j}
$$

Let $G E_{j l}$ be the distribution price of the products sold by the $j$ th producer to the $l$ th consumer; let $\xi_{i j}$ be the volume of green products sold by the $j$ th producer to the market via the $i$ th distributor. Then, the profit of the $j$ th producer, that is, the price difference between end consumers and supplier, can be maximized by

$$
\max B E_{l}=\sum_{l=1}^{e} G E_{j l} \xi_{j l} .
$$

When the market is clear, the volume sold by a producer to market consumers is the sum of the contractual and free sales volumes between the producer and its distributors:

$$
\sum_{l=1}^{e} \xi_{j l}=\sum_{i=1}^{N}\left(\xi_{i j}^{1}+\xi_{i j}^{2}\right)
$$

Let $\xi_{j}^{G E}$ be the maximum sales volume of a producer constrained by its own production capacity. Considering the limited capacity of the producer in distribution or delivery, the upper limit of sales can be defined as

$$
\sum_{l=1}^{e} \xi_{j l} \leq \xi_{j}^{G E}
$$

The profit of the $j$ th producer can be maximized by

$$
\begin{aligned}
& \operatorname{Max} \sum_{l=1}^{e} \xi_{j l} G E_{j l}-\sum_{i=1}^{N}\left(G E_{i j}^{1} \xi_{i j}^{1}+G E_{i j}^{2} \xi_{i j}^{2}\right)-C_{M A-j}\left(T C_{j l}\right), \\
& \operatorname{s.t.}\left\{\begin{array}{l}
\sum_{l=1}^{e} \xi_{j l}=\sum_{i=1}^{N}\left(\xi_{i j}^{1}+\xi_{i j}^{2}\right), \\
\sum_{l=1}^{e} \xi_{j l} \leq \xi_{j}^{G E}, \\
0 \leq \sum_{i=1}^{N} \xi_{i j}^{1} \leq \xi_{j}^{1 G E}, \\
\xi_{j l} \geq 0 .
\end{array}\right.
\end{aligned}
$$

In the producer's profit maximization model (14), the first term is the income of the $j$ th producer by selling green products to distributors and consumers; the second term is the cost of purchasing raw materials from suppliers; the third term is the operating cost of the producer selling green products to distributors and consumers. Let $r$ be the distribution strategy of each distributor. Then, the transaction flow should remain constant in the profit maximization function, according to the Lagrangian function. Let $\delta_{j}$ be the Lagrangian multiplier. Then, the profit maximization model of producer $j$ can be rewritten as

$$
R G_{j}\left(\delta_{j}\right)=\sum_{l=1}^{e} \xi_{j l} G E_{j l}-\sum_{i=1}^{N} \sum_{r=1}^{2} G E_{i j}^{2} \xi_{i j}^{2}-C_{M A-j}\left(T C_{j l}\right)+\delta_{j} \cdot\left(\sum_{i=1}^{N} \sum_{r=1}^{2} \xi_{i j}^{r}-\sum_{l=1}^{e} \xi_{j l}\right)
$$

According to the equivalence between variational inequality and optimization problem, the optimal solution to the producer's profit maximization model (14) is equivalent to the solution to the following variational inequality:

$$
\left(\frac{\partial C_{M A-j}\left(T C_{j l}^{*}\right)}{\partial \xi_{j l}}\right) \cdot\left(\xi_{j l}-\xi_{j l}^{*}\right)+\left(\sum_{i=1}^{N} \sum_{r=1}^{2} G E_{i j}^{r}-\delta_{j}\right) \cdot\left(\xi_{i j}^{r}-\xi_{i j}^{r *}\right)+\left(\sum_{i=1}^{N} \sum_{r=1}^{2} \xi_{i j}^{r}-\sum_{l=1}^{e} \xi_{j l}\right) \cdot\left(\delta_{j}-\delta_{j}^{*}\right) \geq 0
$$

The profit maximization model can be interpreted by optimality conditions. The first part of the model indicates that the producer sells green products sold to its distributors and consumers; the second part means that the producer is willing to purchase raw materials from suppliers; the third part guarantees the conservation of transaction flow at $\delta_{j}^{*}>0$; that is, the producer invests all the purchased raw materials in production and sells out its products. The optimality conditions for all producers can be described as in the following variational inequality: 


$$
\sum_{j=1}^{M} \sum_{l=1}^{e}\left(\frac{\partial C_{M A-j}\left(T C_{j l}^{*}\right)}{\partial \xi_{j l}}+\delta_{j}-G E_{j l}^{*}\right) \cdot\left(\xi_{j l}-\xi_{j l}^{*}\right)+\sum_{j=1}^{M}\left(\sum_{i=1}^{N} \sum_{r=1}^{2} G E_{i j}^{r}-\delta_{j}\right) \cdot\left(\xi_{i j}^{r}-\xi_{i j}^{r *}\right)+\sum_{j=1}^{M}\left(\sum_{i=1}^{N} \sum_{r=1}^{2} \xi_{i j}^{r}-\sum_{l=1}^{e} \xi_{j l}\right) \cdot\left(\delta_{j}-\delta_{j}^{*}\right) \geq 0
$$

3.3. Coordinated Optimization Conditions for the Market Demand Layer. GSCDN is a functional chain that provides distribution services to the green product market. Distribution efficiency and distribution price are the core attributes of the distribution services. Based on these attributes, retailers and consumers select the green products meeting their needs. Let $G E_{l}$ be the highest affordable distribution price of the $l$ th retailer or consumer in the market for the purchase of green products, and let $C_{l}$ be the corresponding transaction cost. In this case, the product demand can be denoted as $\xi_{l}$. Under the Wardrop equilibrium principle of distribution road networks, the $l$ th retailer or consumer in the green product market should satisfy the following conditions in order to select product/distribution service through price comparison:

$$
G E_{j l}^{*}+C_{l}\left(\xi_{j l}^{*}\right) \begin{cases}=G E_{l}, & \xi_{j l}^{*}>0 \\ \geq G E_{l}, & \xi_{j l}^{*}=0\end{cases}
$$

Formula (19) shows that a transaction will take place only if highest affordable price $\xi_{l}$ of the retailer or consumer for product purchase equals the sum between the selling price $G E_{j l}^{*}$ of the distributor and the transaction cost $C_{l} \xi_{j l}^{*}$ of the retailer or consumer to acquire the products; that is, $\xi_{j l}^{*}>0$. If $\xi_{j l}^{*}<0$, no transaction will take place.

In the supply-demand network of green products, the retailers also compete with consumers. The demand for green products is related to the acceptable price of a retailer/ consumer and that of another client. Hence, the demand of the $l$ th retailer or consumer can be expressed as

$$
\xi_{l}=\xi_{l}(B E)
$$

This paper assumes that the green products in the same batch have no quality difference; that is, $B E=\left[B E_{1}, B E_{2}, \ldots\right.$, $\left.B E_{l}\right] \in \mathbb{R}_{+}^{l}$. Then, the optimality conditions for the coordinated optimization of the $l$ th retailer or consumer can be expressed as

$$
\xi_{l}\left(B E^{*}\right)\left\{\begin{array}{l}
=\sum_{j=1}^{M} \xi_{j l}^{*}, \quad G E_{l}^{*}>0, \\
\leq \sum_{j=1}^{M} \xi_{j l}^{*}, \quad G E_{l}^{*}>0 .
\end{array}\right.
$$

Formula (21) shows that if a producer transacts with a retailer/consumer, then $G E_{l}^{*}>0$; in this case, the supply is equal to demand. If $G E_{l}^{*}=0$, then the green products are oversupplied, and the GSCDN management is out of balance.

For all retailers/consumers, $l \in\{1,2, \ldots, e\}$; the equilibrium solution $\left(T C_{j l}^{*}, B E^{*}\right) \in \mathbb{R}_{+}{ }^{M e+e}$ for their behaviors must satisfy the following variational inequality:

$$
\sum_{j=1}^{M} \sum_{l=1}^{e}\left(G E_{j l}^{*}+C_{l}\left(\xi_{j l}^{*}\right)-G E_{l}^{*}\right) \cdot\left(\xi_{j l}-\xi_{j l}^{*}\right)+\sum_{l=1}^{e}\left(\sum_{j=1}^{M} \xi_{j l}^{*}-\xi_{l}(B E *)\right) \cdot\left(G E_{l}-G E_{l}^{*}\right)
$$

3.4. Coordinated Optimization Model for the GSCDN. Under market regulation, the management of GSCDN should reach the ideal equilibrium; that is, all parties of the network should meet supply-demand balance. Specifically, each distributor should balance its supply with sales, each producer should balance its purchase with sales, and each retailer/consumer should purchase its needed products at an affordable price. Further, the entire supply chain network must stay in the state of supply-demand balance. The previous analysis shows that the coordinated optimization conditions for GSCDN are that $\left(T C_{i j}^{1 *}, T C_{i j}^{1 *}, T C_{j l}^{1}, \delta_{j}^{*}\right.$, $\left.G E_{l}^{*}\right) \in \mathbb{R}^{N M+N M+M e+M+e}$ satisfy the following inequality:

$$
\begin{aligned}
& \sum_{i=1}^{N} \sum_{j=1}^{M} \sum_{r=1}^{2}\left(\frac{\partial C_{M A-j}\left(T C_{i j}^{r *}\right)+\partial C_{P R-i}\left(T C_{i j}^{r *}\right)}{\partial \xi_{i j}^{1}}+\delta_{j}\right) \cdot\left(\xi_{i j}^{r}-\xi_{i j}^{r *}\right) \\
& \quad+\sum_{j=1}^{M} \sum_{l=1}^{e}\left(\frac{\partial C_{M A-j}\left(Q_{i j}^{r *}\right)}{\partial \xi_{j l}}+\delta_{j}+C_{l}\left(\xi_{i j}^{*}\right)-G E_{l}^{*}\right) \cdot\left(\xi_{j l}-\xi_{i j}^{*}\right) \\
& \quad+\sum_{j=1}^{M}\left(\sum_{i=1}^{N} \sum_{r=1}^{2} \xi_{i j}^{r}-\sum_{l=1}^{e} \xi_{j l}\right) \cdot\left(\delta_{j}-\delta_{j}^{*}\right)+\sum_{l=1}^{e}\left(\sum_{j=1}^{M} \xi_{j l}^{*}-\xi_{l}(B E *)\right) \cdot\left(G E_{l}-G E_{l}^{*}\right) \geq 0 .
\end{aligned}
$$




\section{Coordinated Optimization Mechanism under the Profit-Sharing Contract}

The profit-sharing contract allows the parties to share the total profit of the network by a certain proportion. Under this contract, the distributors and producers have the same objective of coordinated cooperation. During GSCDN management, the $i$ th distributor can have $\eta_{j}$ of the total profit, while the $j$ th producer can have $\left(1-\eta_{i j}\right)$ of the total profit. Under the profit-sharing contract, $\left(T C_{i j}^{*}, T C_{j l}^{*}, \delta_{j}^{*}\right.$, $\left.G E_{l}^{*}\right) \in \mathbb{R}^{N M+N M+M e+M+e}$ satisfy the coordinated optimization model for the GSCDN:

$$
\begin{aligned}
& \sum_{i=1}^{N} \sum_{j=1}^{M}\left(\frac{\partial C_{M A-j}\left(T C_{i j}^{r *}\right)+\partial C_{P R-i}\left(T C_{i j}^{r *}\right)}{\partial \xi_{i j}}+\delta_{j}^{*}\right) \cdot\left(\xi_{i j}-\xi_{i j}^{r *}\right) \\
& \quad+\sum_{j=1}^{M} \sum_{l=1}^{e}\left(\frac{\partial C_{M A-j}\left(T C_{j l}^{*}\right)}{\partial \xi_{j l}}+\delta_{j}^{*}+C_{l}\left(\xi_{j l}^{*}\right)-G E_{l}^{*}\right) \cdot\left(\xi_{j l}-\xi_{j l}^{*}\right) \\
& \quad+\sum_{j=1}^{M}\left(\sum_{i=1}^{N} \xi_{i j}-\sum_{l=1}^{e} \xi_{j l}\right) \cdot\left(\delta_{j}-\delta_{j}^{*}\right)+\sum_{l=1}^{e}\left(\sum_{j=1}^{M} \xi_{j l}^{*}-\xi_{l}(B E *)\right) \cdot\left(G E_{l}-G E_{l}^{*}\right) \geq 0 .
\end{aligned}
$$

Considering the operating capacity of each enterprise, the equilibrium solution to formula (24) must satisfy an additional constraint:

$$
\left\{\begin{array}{l}
\sum_{j=1}^{M} \xi_{i j} \leq \xi_{i}^{G E} \\
\sum_{l=1}^{e} \xi_{j l} \leq \xi_{j}^{G E} \\
\left(\xi_{i j}, \xi_{j l}, \delta_{j}, G E_{l}\right) \geq 0 .
\end{array}\right.
$$

Under the profit-sharing contract, the total profit on a distributor-producer subchain can be calculated by

$$
\begin{aligned}
& R G_{i j}\left(\frac{\xi_{i j}}{\sum_{i=1}^{N} \xi_{i j}}\right) \cdot\left(\sum_{l=1}^{e} \xi_{j l} G E_{j l}--C_{M A-j}\left(T C_{j l}\right)\right)-\frac{\xi_{i j}}{\xi_{i}}\left(C_{M A-j}\left(T C_{i j}\right)+C_{P R-i}\left(T C_{i j}\right)\right) \\
& \text { s.t. }\left\{\begin{array}{l}
\sum_{l=1}^{e} \xi_{j l}=\sum_{i=1}^{N} \xi_{i j}, \\
\xi_{j l} \geq 0 .
\end{array}\right.
\end{aligned}
$$

The profit obtained by the $i$ th distribution and that obtained by the $j$ th producer can be, respectively, described by

$$
\begin{aligned}
R G_{i} & =\sum_{j=1}^{M} \eta_{i j} R G_{i j}, \\
R G_{j} & =\sum_{i=1}^{M}\left(1-\eta_{i j}\right) R G_{i j} .
\end{aligned}
$$

\section{Model Solving}

This paper proposes an adaptive genetic algorithm to solve the above model. The crossover and mutation operators, which determine the convergence of the algorithm, can be adjusted dynamically. Let $g_{\max }$ and $g_{\min }$ be the maximum and minimum fitness of the population, respectively; let $g$ ' and $g$ be the fitness of crossover individuals and mutation individuals, respectively; let $g^{*}$ be the mean fitness of the population; let $W_{T \text { max }}$ and $W_{T \text { min }}$ be the maximum and 
minimum crossover probabilities, respectively; let $W_{D \max }$ and $W_{D \text { min }}$ be the maximum and minimum mutation probabilities, respectively. Then, we have

$$
W_{T}=\left\{\begin{array}{l}
W_{T \max }, \quad g^{\prime}<g^{*}, \\
W_{T \max }-\left(g^{\prime}-g^{*}\right) /\left(g_{\max }-g_{\min }\right), \quad g^{\prime} \geq g^{*}, g_{\max } \neq g_{\min }, \\
W_{T \min }, \quad g^{\prime} \geq g^{*}, g_{\max }=g_{\min } .
\end{array}\right.
$$

$$
W_{D}= \begin{cases}W_{D \max }, & g<g^{*}, \\ W_{D \text { min }}, & g \geq g^{*}\end{cases}
$$

The proposed adaptive genetic algorithm can be implemented in the following steps:

Step 1. Initialize the solving algorithm, set the population size and the termination conditions, and encode the subjects in the network, as well as their behaviors, prices, and sales.

Step 2. Set the initial number of iterations to zero, and randomly generate the initial population $U(0)$.

Step 3. Compute the fitness of each chromosome $g=1$ / $\left(Z+\sum W\right)$.

Step 4. Select $U(T+1)$ from $U(T)$ by roulette wheel selection, and save the optimal solution by the elite strategy.

Step 5. Compute $W_{D}$ and $W_{T}$ by formulas (28) and (29), respectively.

Step 6. Implement crossover and mutation of chromosomes.

Step 7. Set the number of iterations to $T=T+1$.

Step 8. End the iterations when the termination conditions are satisfied; otherwise, return to Step 3.

\section{Experiments and Results' Analysis}

Under the profit-sharing contract, the game between the relevant parties only focuses on profit allocation, when the complex network management is being optimized. Therefore, the sale volumes, transaction prices, and the total profits of producer-distributor subchain were calculated by the aforementioned functions about the operating behaviors and incomes of relevant parties in GSCDN. The computed results are presented in Tables $1-3$.

From the tables, it can be seen that the enterprises in each layer of GSCDN were consistent in coordinated optimization state, using the eigenfunctions of these enterprises. Under the profit-sharing contract, the producers and distributors had the same total profit in the subchain. Retailer 5, a member of the e-commerce demand group, made a small profit per transaction but earned a lot with the largest trading volume. The supply to this retailer is the priority of distribution services. By contrast, consumer 8 had a low elasticity in terms of green product demand. Despite a high profit per unit transaction, the consumer had a small trading volume.

In actual economic activities, producers vary with business philosophy, production capacity, production process, and so forth. It is important to study how the different costs of producers influence the coordinated optimization of the management of the complex system for the GSCDN. Hence, the cost function of a producer was changed to analyze the influence. Similarly, the operating cost of distributors also differs with business philosophy, distribution model, and operating scale. Thus, the cost function of a distributor was adjusted to examine its influence on the coordinated optimization state of the complex system management. After the cost functions of producer and distributor are adjusted, the sale volumes, transaction prices, and the total profits of producer-distributor subchain were recalculated (Tables $4-6$ ).

As shown in Tables 4-6, the coordinated optimization results could be compared after the cost of producer 1 and that of distributor 3 were increased. The comparison shows that, under a stable market demand for green products, producer 1 cut down the supply of green products due to cost hike. Then, the supply-demand imbalance caused the price of green products to rise and eventually reach the equilibrium. Hence, the green products became pricier, and the sales volume decreased. Facing the rising selling price of producer, distributor 3 needed to pay more for stock replenishment and thus purchased fewer green products. Distributor 4 sold more green products, owing to its cost advantage. During the coordinated optimization of GSCDN management, the total profit of the subchain of producer 1 plunged, while that of the subchain of producer 2 rose to a certain extent.

For the subchain with a vibrant market demand for green products, the local government often subsidizes the relevant producers and sellers to reduce their operating costs of green supply chain, aiming to promote green product transactions. In general, the local subsidies are coupled with the sales volume of the target enterprise. In the presence of government subsidy, the sale volumes, transaction prices, and the total profits of producer-distributor subchain were recalculated (Tables 7-9).

Under government subsidy, producer 1 saw a marked decline in cost. The falling cost promoted the producer's sales of green products. For producer 2, the green product sales dropped by a certain extent, due to the decline in competitiveness. Overall, the falling cost of producer 1 brought a decrease to the profit of other subchains. However, the government subsidy of green products greatly enhanced the green product sales of the entire complex system. As a result, the transaction prices of retailers/consumers decreased, while the market welfare increased.

To further verify the proposed model and algorithm, it is assumed that the distribution center of a distributor in the complex system provides retailers and consumers with distribution services. The distribution center classifies the retailers and consumers by the type of green products and distributes the corresponding products to each type of 
TABLE 1: Green product sales volumes in the GSCDN.

\begin{tabular}{lcccccc}
\hline Sales volume/10,000 & Producer 1 & Producer 2 & Retailer 5 & Retailer 6 & Consumer 7 & Consumer 8 \\
\hline Distributor 3 & 83.25 & 85.25 & 101.67 & 34.82 & 35.16 & 0 \\
Distributor 4 & 83.25 & 85.25 & 101.67 & 34.82 & 35.16 & 0 \\
Supply-demand ratio & 167.63 & 169.68 & 202.94 & 68.30 & 68.30 & 0 \\
\hline
\end{tabular}

TABLE 2: Transaction prices of green products in the GSCDN.

\begin{tabular}{lcccccc}
\hline Transaction price/yuan & Producer 1 & Producer 2 & Retailer 5 & Retailer 6 & Consumer 7 & Consumer 8 \\
\hline Distributor 3 & 431.62 & 431.62 & 536.37 & 472.95 & 472.95 & 398.21 \\
Distributor 4 & 431.62 & 431.62 & 536.37 & 472.95 & 472.95 & 398.21 \\
\hline
\end{tabular}

TABLe 3: Total profits of the producer-distributor subchain through coordinated optimization under the profit-sharing contract.

\begin{tabular}{lcr}
\hline Total profit/10,000 yuan & Producer 1 & Producer 2 \\
\hline Distributor 3 & $16,967.47$ & $16,967.47$ \\
Distributor 4 & $16,967.47$ & $16,967.47$ \\
\hline
\end{tabular}

TABLE 4: Green product sales volumes in the GSCDN after the adjustment of cost functions.

\begin{tabular}{lcccccc}
\hline Sales volume/10,000 & Producer 1 & Producer 2 & Retailer 5 & Retailer 6 & Consumer 7 & Consumer 8 \\
\hline Distributor 3 & 75.32 & 75.32 & 75.32 & 37.46 & 37.46 & 2.86 \\
Distributor 4 & 83.54 & 86.26 & 109.41 & 32.72 & 31.55 & 0 \\
Supply-demand ratio & 158.67 & 162.78 & 181.63 & 68.51 & 68.21 & 2.86 \\
\hline
\end{tabular}

TABLE 5: Transaction prices of green products in the GSCDN after the adjustment of cost functions.

\begin{tabular}{lcccccc}
\hline Transaction price/yuan & Producer 1 & Producer 2 & Retailer 5 & Retailer 6 & Consumer 7 & Consumer 8 \\
\hline Distributor 3 & 375.21 & 375.21 & 546.83 & 462.75 & 462.75 & 396.20 \\
Distributor 4 & 428.93 & 426.39 & 546.83 & 462.75 & 462.75 & 396.20 \\
\hline
\end{tabular}

TABLE 6: Total profits of the producer-distributor subchain through coordinated optimization under the profit-sharing contract after the adjustment of cost functions.

\begin{tabular}{lcc}
\hline Total profit $/ 10,000$ yuan & Producer 1 & Producer 2 \\
\hline Distributor 3 & $12,310.97$ & $17,362.13$ \\
Distributor 4 & $10,275.20$ & $17,821.06$ \\
\hline
\end{tabular}

TABLE 7: Green product sales volumes in the GSCDN under government subsidy.

\begin{tabular}{lcccccc}
\hline Sales volume/10,000 & Producer 1 & Producer 2 & Retailer 5 & Retailer 6 & Consumer 7 & Consumer 8 \\
\hline Distributor 3 & 74.32 & 75.46 & 77.43 & 37.20 & 37.20 & 3.65 \\
Distributor 4 & 85.43 & 86.72 & 109.72 & 31.45 & 31.45 & 0 \\
Supply-demand ratio & 158.76 & 162.50 & 185.35 & 68.12 & 68.12 & 3.65 \\
\hline
\end{tabular}

TABLE 8: Transaction prices of green products in the GSCDN under government subsidy.

\begin{tabular}{lcccccc}
\hline Transaction price/yuan & Producer 1 & Producer 2 & Retailer 5 & Retailer 6 & Consumer 7 & Consumer 8 \\
\hline Distributor 3 & 379.24 & 379.24 & 545.98 & 467.61 & 467.61 & 382.65 \\
Distributor 4 & 435.31 & 435.31 & 545.98 & 467.61 & 467.61 & 382.65 \\
\hline
\end{tabular}


TABLE 9: Total profits of the producer-distributor subchain through coordinated optimization under the profit-sharing contract under government subsidy.

\begin{tabular}{lcc}
\hline Total profit $/ 10,000$ yuan & Producer 1 & Producer 2 \\
\hline Distributor 3 & $11,510.07$ & $17,263.52$ \\
Distributor 4 & $10,295.39$ & $17,330.40$ \\
\hline
\end{tabular}

TABLE 10: Time windows for the distribution to retailers/consumers.

\begin{tabular}{|c|c|c|c|c|c|}
\hline Serial number & Time window & Serial number & Time window & Serial number & Time window \\
\hline 1 & {$[5,12]$} & 8 & {$[51,56]$} & 15 & {$[70,80]$} \\
\hline 2 & {$[9,17]$} & 9 & {$[55,60]$} & 16 & {$[75,85]$} \\
\hline 3 & {$[23,31]$} & 10 & {$[60,65]$} & 17 & {$[85,90]$} \\
\hline 4 & {$[29,36]$} & 11 & {$[65,70]$} & 18 & {$[65,75]$} \\
\hline 5 & {$[31,39]$} & 12 & {$[75,85]$} & 19 & {$[70,85]$} \\
\hline 6 & {$[40,45]$} & 13 & {$[85,90]$} & 20 & {$[90,95]$} \\
\hline 7 & {$[45,50]$} & 14 & {$[90,95]$} & & \\
\hline
\end{tabular}

TABLE 11: Initial green product demands of retailers/consumers.

\begin{tabular}{lcccccccccc}
\hline Serial number & 1 & 2 & 3 & 4 & 5 & 6 & 7 & 8 & 9 \\
\hline Demand/10,000 & 1 & 3 & 3 & 3 & 2 & 3 & 1 & 2 & 1 \\
Serial number & 11 & 12 & 13 & 14 & 15 & 16 & 17 & 18 & 19 & 20 \\
Demand/10,000 & 3 & 2 & 1 & 1 & 1 & 2 & 3 & 3 & 2 & 1 \\
\hline
\end{tabular}

TABLE 12: Mean target values of all solutions and the target values of the final solutions.

\begin{tabular}{lccc}
\hline Serial number & Target value of final solutions & Mean target value of all solutions & Gap (\%) \\
\hline 1 & 125.8 & 327.6 & 56 \\
2 & 126.9 & 328.9 & 57 \\
3 & 119.5 & 315.12 & 63.5 \\
4 & 136.4 & 306.36 & 57.2 \\
5 & 125 & 317.48 & 56.3 \\
6 & 125 & 308.24 & 61.6 \\
7 & 131 & 305.7 & 57.8 \\
8 & 113 & 314.8 & 64.5 \\
9 & 117.2 & 328.62 & 63.1 \\
10 & 129.3 & 315.75 & 59.2 \\
\hline
\end{tabular}

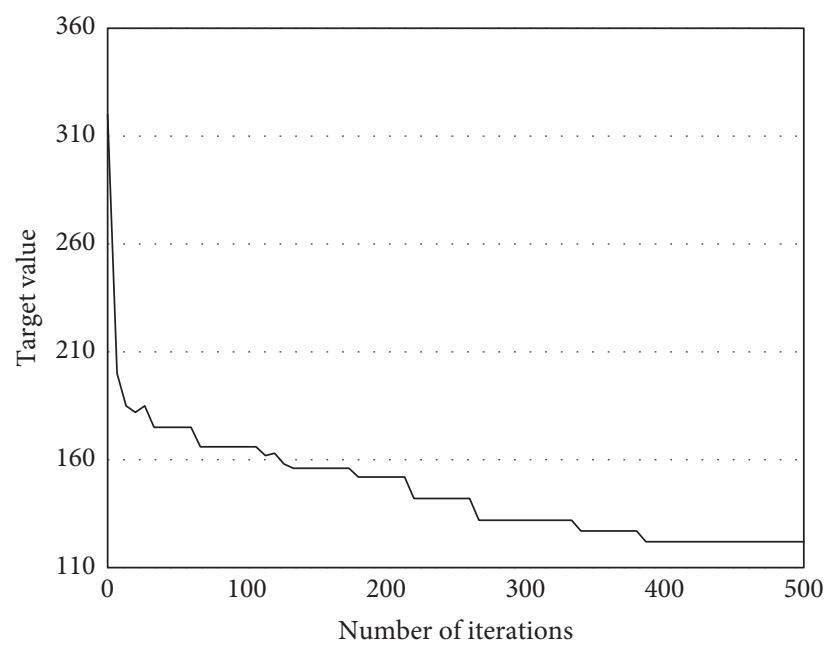

Figure 5: Convergence curve of our solving algorithm. 
retailers/consumers. Tables 10 and 11 provide the distribution time windows and initial green product demands of retailers/consumers.

The genetic algorithm searches for the solution to the target model, starting with the string set of solutions. Therefore, the heuristic algorithm might yield different results for the same model. Before implementing our solving algorithm, it is necessary to compute and compare the target value of the final solution to our model with the mean target value of all solutions. This is the way to test the effectiveness of our coordinated optimization model and its solving algorithm. The relevant results (Table 12) show that the final solutions had very small differences with each other and saved about $60 \%$ of distribution price compared with the mean target value of all solutions. Therefore, our model and its solving algorithm were proved effective. Figure 5 presents the convergence curve of the solving algorithm. As shown in Figure 5 and Table 12, our model achieved ideal convergence and mean target value, which verify the correctness of the model.

\section{Conclusions}

This paper mainly derives a coordinated optimization model for the complex system of GSCDN. Based on the proposed structure and game logic of the network, the upper limit was deduced for the sales volume of the producer, under the constraint of the producer's limited production capacity. Next, the coordinated optimization conditions were determined for the distributor layer, the producer layer, and the market demand layer, and the coordinated optimization model was established for the complex system. Further, the coordinated optimization mechanism of the complex system was provided under the profit-sharing mechanism. After that, the operating process of the complex system was simulated through experiments, and the sales volumes, transaction prices, and the total profits of producer-distributor subchains were computed after the adjustment of cost functions and the green subsidies by the government. The distribution time windows and initial green product demands of retailers/ consumers were presented. In addition, the mean target values of all solutions and the target value of the final solution were computed. The results fully demonstrate the effectiveness of our distribution optimization model and its solving algorithm.

\section{Data Availability}

The data used to support the findings of this study are available from the corresponding author upon request.

\section{Conflicts of Interest}

The authors declare that they have no conflicts of interest regarding the publication of this paper.

\section{Acknowledgments}

This study was supported by Hundreds of Schools Unite with Hundreds of Counties-University Serving Rural
Revitalization Science and Technology Support Action Plan (Grant no. BXLBX0847), Hubei Self-Science Fund Project (Grant name: brain tumor diagnosis based on capsule neural network), and National Statistical Science Research Project in 2020, China (Grant no. 2020LY023).

\section{References}

[1] C. Lan, "A coordination contract for green agricultural product supply chain with stochastic output," Journal Européen des Systèmes Automatisés, vol. 52, no. 4, pp. 347-354, 2019.

[2] D. X. Huo, X. J. Xiao, and Y. J. Pan, "Multi-objective energysaving job-shop scheduling based on improved NSGA-II," International Journal of Simulation Modelling, vol. 19, no. 3, pp. 494-504, 2020.

[3] D. Wei, "Modeling and simulation of a multi-agent green supply chain management system for retailers," Journal Européen des Systèmes Automatisés, vol. 53, no. 4, pp. 549-557, 2020.

[4] Y. Wang, J. Zhang, X. Guan, M. Xu, Z. Wang, and H. Wang, "Collaborative multiple centers fresh logistics distribution network optimization with resource sharing and temperature control constraints," Expert Systems with Applications, vol. 165, Article ID 113838, 2021.

[5] H. N. Quang and T. D. Huu, "Factors preventing the way to success of the retail supply chain," Journal of System and Management Sciences, vol. 9, no. 2, pp. 114-122, 2019.

[6] A. J. Freile, J. Mula, and F. Campuzano-Bolarin, "Integrating inventory and transport capacity planning in a food supply chain," International Journal of Simulation Modelling, vol. 19, no. 3, pp. 434-445, 2020.

[7] A. Aleksic, M. Runic Ristic, N. Komatina, and D. Tadic, "Advanced risk assessment in reverse supply chain processes: a case study in Republic of Serbia," Advances in Production Engineering \& Management, vol. 14, no. 4, pp. 421-434, 2019.

[8] X. W. Shen, S. Z. Zhu, J. H. Zheng, Y. D. Han, Q. S. Li, and J. Nong, "Active distribution network planning-operation cooptimization considering the coordination of ESS and DG," Power System Technology, vol. 39, no. 7, pp. 1913-1920, 2015.

[9] Y. Zhu, J. Wang, and M. Li, "Collaborative distribution in the soft time window of agricultural-means supply chain based on simulated annealing-genetic algorithm," Journal Européen des Systèmes Automatisés, vol. 53, no. 6, pp. 835-844, 2020.

[10] A. Ali, M. U. Keerio, and J. A. Laghari, "Optimal site and size of distributed generation allocation in radial distribution network using multi-objective optimization," Journal of Modern Power Systems and Clean Energy, vol. 9, no. 2, pp. 404-415, 2020.

[11] A. De Corte and K. Sörensen, “An Iterated Local Search Algorithm for multi-period water distribution network design optimization," Water, vol. 8, no. 8, p. 359, 2016.

[12] S. K. Injeti, V. K. Thunuguntla, and M. Shareef, "Optimal allocation of capacitor banks in radial distribution systems for minimization of real power loss and maximization of network savings using bio-inspired optimization algorithms," International Journal of Electrical Power \& Energy Systems, vol. 69, pp. 441-455, 2016.

[13] A. Markana, G. Trivedi, and P. Bhatt, "Multi-objective optimization based optimal sizing \& placement of multiple distributed generators for distribution network performance improvement," RAIRO-Operations Research, vol. 55, no. 2, pp. 899-919, 2021.

[14] O. AlAhmad and M. AlDahmi, "A review of operation planning and distribution network optimization of AADC 
network," in Proceedings of the 2021 IEEE International Conference in Power Engineering Application (ICPEA), pp. 216-220, Busan, South Korea, October 2021.

[15] I. U. Munasinghe and T. D. Rupasinghe, "A supply chain network design optimization model from the perspective of a retail distribution supply chain," in Proceedings of the 2016 Manufacturing \& Industrial Engineering Symposium (MIES), pp. 1-5, Colombo, Sri Lanka, October 2016.

[16] M. Mosbah, R. D. Mohammedi, S. Arif, and A. Hellal, "Optimal of shunt capacitor placement and size in Algerian distribution network using particle swarm optimization," in Proceedings of the 2016 8th International Conference on Modelling, Identification and Control (ICMIC), pp. 192-197, Algiers, Algeria, November 2016.

[17] N. Holjevac, M. Zidar, and I. Kuzle, "Techno-economic assessment and optimization of the energy storage unit in the distribution network," in Proceedings of the IEEE EUROCON 2019-18th International Conference on Smart Technologies, pp. 1-6, Novi Sad, Serbia, July 2019.

[18] H. Liao, "Review on distribution network optimization under uncertainty," Energies, vol. 12, no. 17, p. 3369, 2019.

[19] A. De Corte and K. Sörensen, "An iterated local search algorithm for water distribution network design optimization," Networks, vol. 67, no. 3, pp. 187-198, 2016.

[20] S. Li, T. Yu, T. Pu, J. Ming, and S. Fan, "Coordinated optimization control method of transmission and distribution network,", in Proceedings of the 2016 IEEE PES Asia-Pacific Power and Energy Engineering Conference (APPEEC), pp. 2215-2219, Wuhan, China, March 2016.

[21] C. Siew, T. T. Tanyimboh, and A. G. Seyoum, "Penalty-free multi-objective evolutionary approach to optimization of Anytown water distribution network," Water Resources Management, vol. 30, no. 11, pp. 3671-3688, 2016.

[22] R. E. Rasi and D. Hatami, "Environmental risk and innovation in supply chain: analysis of influence of supply chain agility," Journal of System and Management Sciences, vol. 9, no. 3, pp. 1-25, 2019.

[23] C. Kogler and P. Rauch, "Game-based workshops for the wood supply chain to facilitate knowledge transfer," International Journal of Simulation Modelling, vol. 19, no. 3, pp. 446-457, 2019.

[24] M. Heidarifar, P. Andrianesis, and M. Caramanis, "A Riemannian optimization approach to the radial distribution network load flow problem," Automatica, vol. 129, Article ID 109620, 2021.

[25] W. Wu, W. Liu, F. N. Zhang, and V. Dixit, "A new flexible parking reservation scheme for the morning commute under limited parking supplies," Networks And Spatial Economics, vol. 96, 2021.

[26] J. Wu, C. Shi, M. Shao et al., "Reactive power optimization of a distribution system based on scene matching and deep belief network," Energies, vol. 12, no. 17, p. 3246, 2019.

[27] H. Monsef, M. Naghashzadegan, A. Jamali, and R. Farmani, "Comparison of evolutionary multi objective optimization algorithms in optimum design of water distribution network," Ain Shams Engineering Journal, vol. 10, no. 1, pp. 103-111, 2019.

[28] R. Stekelorum, I. Laguir, S. Gupta, and S. Kumar, "Green supply chain management practices and third-party logistics providers' performances: a fuzzy-set approach," International Journal of Production Economics, vol. 235, p. 108093, 2021.

[29] J. Wu, "Guang Research on decision modeling and management optimization of insurance reserve in logistics center under green supply chain management," in Proceedings of the 9th International Conference on Logistics and Systems Engineering, pp. 152-160, Barcelona, Spain, October 2019. 